\title{
Image guided audit of surgery for temporal lobe epilepsy
}

\author{
N D Kitchen, M J Cook, S D Shorvon, D R Fish, D G T Thomas
}

\begin{abstract}
Studies on surgery for temporal lobe epilepsy are hampered by lack of information about the actual surgery that has taken place. A method is described for accurately measuring the volumes of resection by MRI after surgery. Ten cases of surgically treated temporal lobe epilepsy (nine non-tailored resections, one selective amygdalohippocampectomy) are presented to show the technique. Indices of extent of resection in both the mesiobasal and lateral temporal lobe compartments have been measured, compared, and evaluated. By comparison with identical preoperative volumetric MRI the hippocampal resections have been correlated with the demonstrated hippocampal volume loss, thought to be of relevance in the aetiology of temporal lobe epilepsy. Detailed postoperative audit in this manner is vital in providing a rational basis for follow up studies of outcome.
\end{abstract}

(F Neurol Neurosurg Psychiatry 1994;57:1221-1227)

The surgical treatment of medically refractory temporal lobe epilepsy secondary to hippocampal sclerosis is a well recognised and often highly successful form of treatment ${ }^{1-10}$ with long term seizure control obtained in $60-80 \%$ of cases. The optimum surgical resection remains elusive, however, despite attempts to tailor resections to electrophysio-

Institute of Neurology and National Hospital for Neurology and Neurosurgery, Queen Square, London, UK Department of Neurological Surgery N D Kitchen D G T Thomas

Department of Clinical Neurology M J Cook

$S$ D Shorvon

D R Fish

Department of Clinical

Neurophysiology

D R Fish

Correspondence to: Mr N D Kitchen,

Department of Neurological Surgery, Institute of

Surgery, Institute of

Lourology, Queen Square,

Received 6 December 1993 and in revised form

6 April 1994.

Accepted 3 May 1994 logical and neuroradiological abnormalities. In particular there is uncertainty over the extent of the resection that is required of the mesiobasal $v$ the lateral neocortical structures to maximise the efficacy of the seizure control while causing minimum neuropsychological morbidity. There are essentially two surgical approaches: firstly, anterior temporal lobectomy (either as a standardised operation or with some tailoring of the resection dependent on the intraoperative electrocorticography ${ }^{11}$ ); secondly, more selective resections either of the mesiobasal structures or lateral neocortex localised by preoperative imaging and electrophysiology. Although anterior temporal lobectomy, developed some 40 years ago, ${ }^{12-14}$ remains the gold standard and the routine operation in most centres there is a trend towards the more local procedures where a minimal brain resection is attempted without compromising seizure control. In this regard the concept of selective resection of the mesiobasal temporal structures is not new. ${ }^{15}$ More recently, however, several units have developed selective mesiobasal resections ${ }^{16-20}$ in the belief that lateral neocortical resection may be unecessary for seizure control and can cause postoperative memory deficits especially in neuropsychologically compromised patients. Conversely, a minority of neurosurgeons perform solely lateral neocortical resections with comparable results. ${ }^{21}$

The use of preoperative high resolution volumetric MRI has had an enormous impact on epilepsy surgery planning in general. ${ }^{22-26}$ Thus far, however, there has been limited interest in the systematic analysis of the postoperative appearances. ${ }^{87-32}$ This is an important omission as with the advent of high resolution MRI an objective record of the operative resection is now possible that would not only give technical feedback to the surgeon, but would also give an anatomical basis to outcome studies. In this paper we describe a method for measuring the volumes of resec-
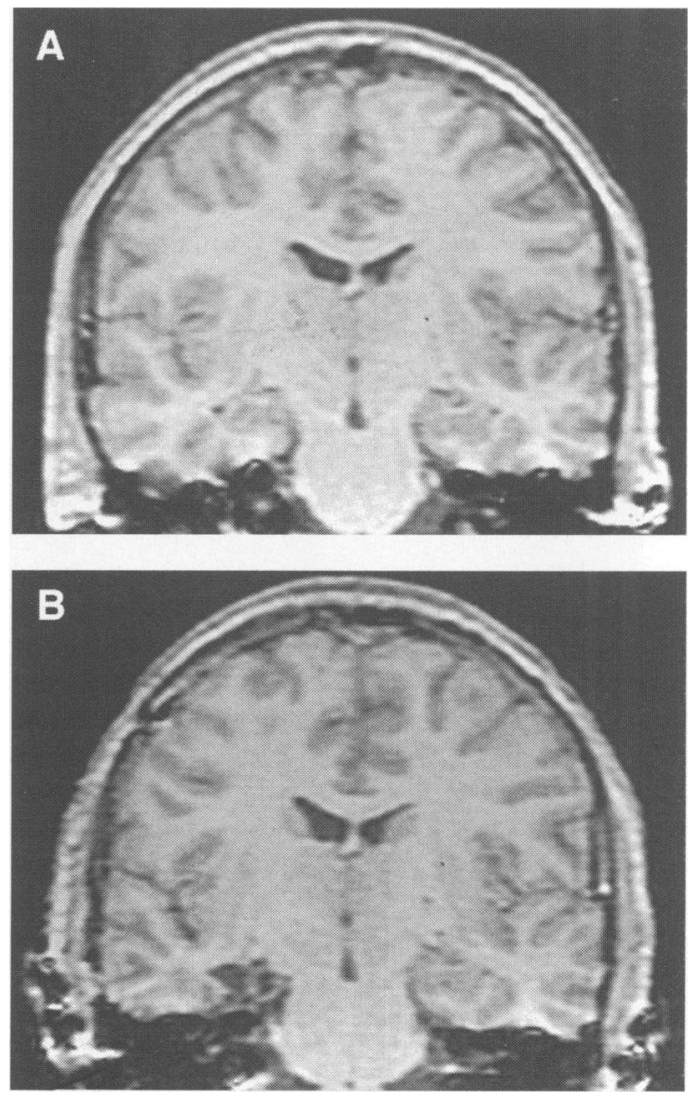

Figure 1 (A) Preoperative and (B) postoperative MRI; volumetric sequence (coronal T1 $1.5 \mathrm{~mm}$ thick images) with equivalent slices $18 \mathrm{~mm}$ (12 slices) anterior to the posterior hippocampal limit. 

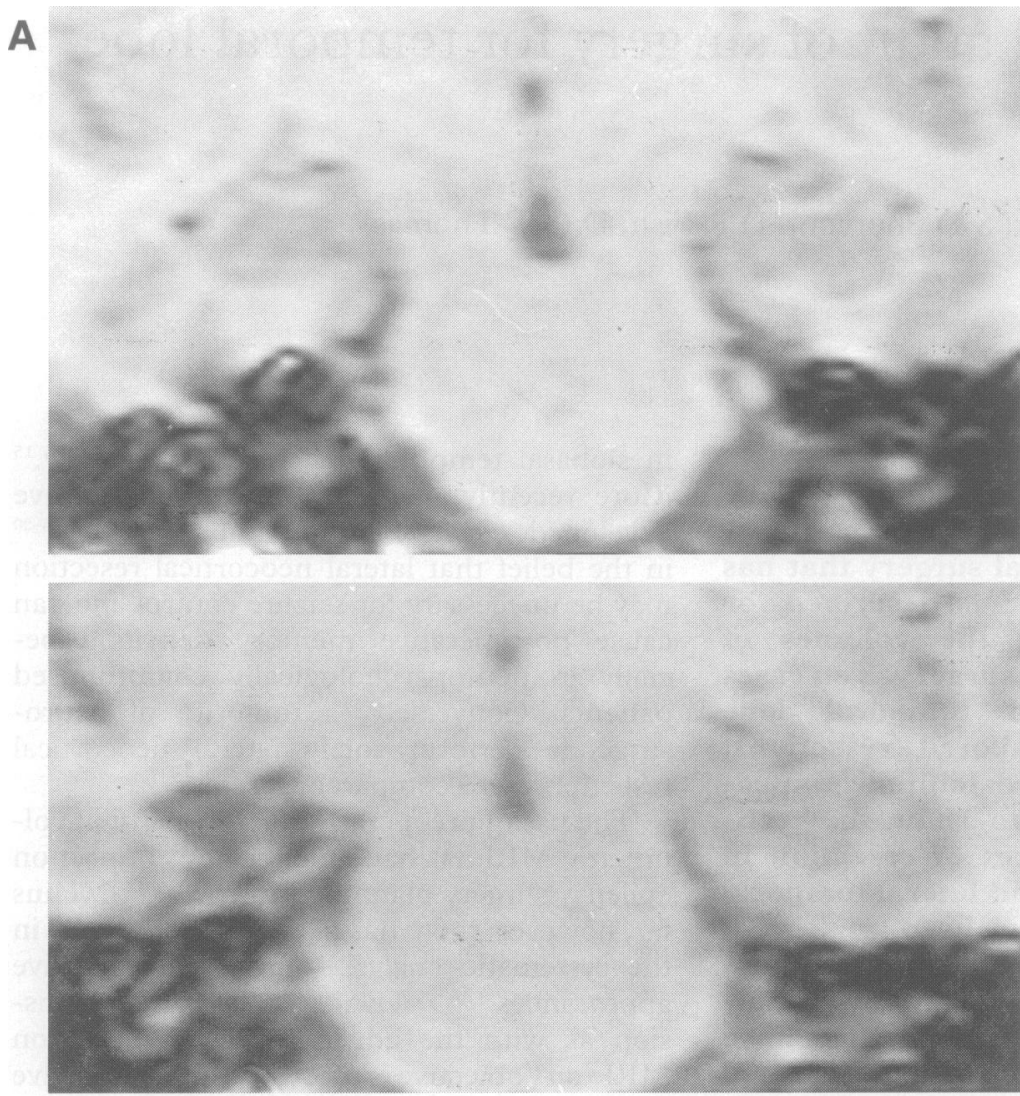

B
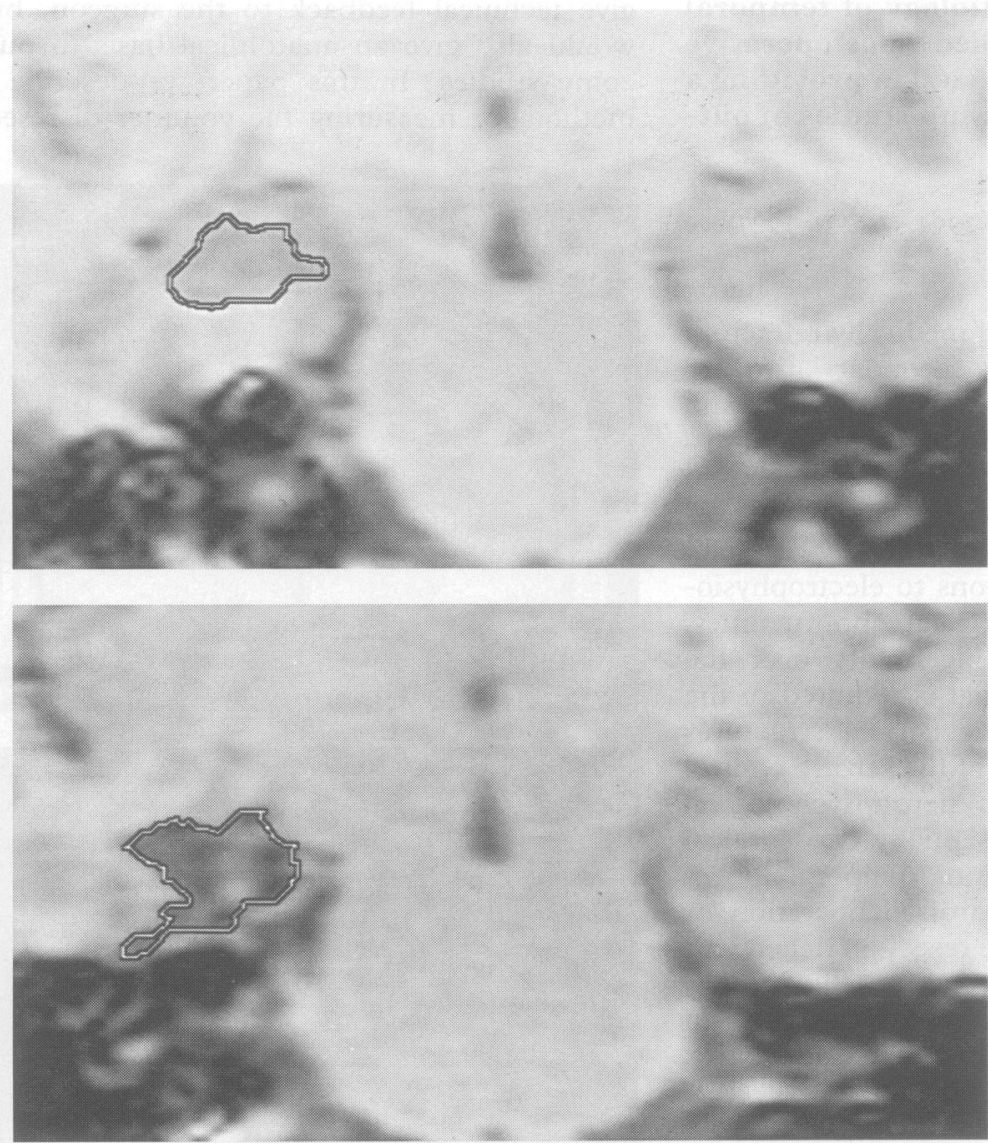

Figure 2 Preoperative and postoperative MRI (same images as fig 1 with the area of interest enlarged). Figure $2 A$ shows the hippocampus to be resected (upper left) and the resultant resection (lower left). In figure $2 B$ these have been manually drawn around to calculate the corresponding areas. In this instance in the preoperative study the hippocampus only has been outlined, whereas in the postoperative study the resection is seen to include all the hippocampal formation (including alveus and fimbria) and parahippocampal gyrus. Figures 1 and 2 are from case 2 and are indicated on the morphometric resection graph (fig 4, case 2) by the small middle arrow. tion of the mesiobasal and lateral compartments of the temporal lobe after surgery for temporal lobe epilepsy. These volumetric measurements are also compared with linear estimates of resection magnitude as it is our belief that only volumetric indices can give an accurate assessment of the amount and position of brain resection. Finally, by comparing with preoperative hippocampal volumetric morphometry, a correlation between the preoperative hippocampal volume loss shown on MRI and the site of resection has been performed.

\section{Patients and methods}

Ten patients with medically intractable temporal lobe epilepsy underwent postoperative volumetric MRI three months after surgery. All had undergone an identical volumetric MRI study before their resective surgery. There were six women and four men with a mean age of 32.5 (range 18-45) years. All had chronic temporal lobe epilepsy with a mean seizure history of $16 \cdot 2$ (range 5-30) years. Clinical, electrophysiological, and imaging features were concordant in every case (five left temporal lobe epilepsy; five right temporal lobe epilepsy). In nine patients surgery consisted of a non-tailored anterior temporal lobectomy and in one patient (case 9) a stereotactic amygdalohippocampectomy was performed. Cases 1 to 4 were performed by surgeon " $A$ " and the remainder by surgeon " $B$ ". The histopathological diagnosis from the surgical specimens examined was hippocampal sclerosis in nine and non-specific pathological change in one.

The MRI sequence protocols before and after operation were identical and have previously been validated and described in detail ${ }^{23} 2930$ as has the method of assessing the hippocampal volume before operation. ${ }^{23}$ Briefly, the imaging protocol was as follows (figs 1 and 2). A 1.5 Tesla G E Signa Unit (General Electric Medical Systems, Milwaukee, USA) was used in all cases. The volumetric imaging was performed in the coronal plane with a T1 weighting and a spoiled echo gradient technique; 124 contiguous $1 \mathrm{~mm}$ thick slices were thus obtained throughout the entire head. Also, sagittal $\mathrm{T} 1$ and axial $\mathrm{T} 2$ and proton density weighted series were obtained with a slice thickness of $5 \mathrm{~mm}$, and an interslice gap. of $2.5 \mathrm{~mm}$. Image analysis took place in the scanning suite on an adjacent IGE IC workstation. The coronal images through the operation site were magnified $\times 2.5$ (fig 2 ) and the resection margin was outlined manually with a tracker ball driven cursor (fig 2B). The enclosed area was then automatically calculated by pixel counting. Summation of the resection areas in the slices through the operation site allowed the total resection volume to be easily calculated (by a multiplication factor of 1.5 , the $\mathrm{mm}$ thickness of the contiguous slices). The coronal, sagittal, and axial series were then analysed to study the anatomy of resection in three planes and linear measurements (fig 3 ) made on the console screen. 
Figure 3 Axial $5 \mathrm{~mm} \mathrm{T2}$ weighted MRI. The linear measurements of the resection extent $(1$, direct measurement to the temporal pole; 2 , orthogonal measurement along the axis of the temporal lobe to the pole) are shown. The linear measurements are similar to those sometimes taken by the surgeon at operation. The angle of the ruler with respect to the temporal lobe and the angle and irregularity of the resection margin (marked in this image) all contribute to the inherent inaccuracy of the technique.

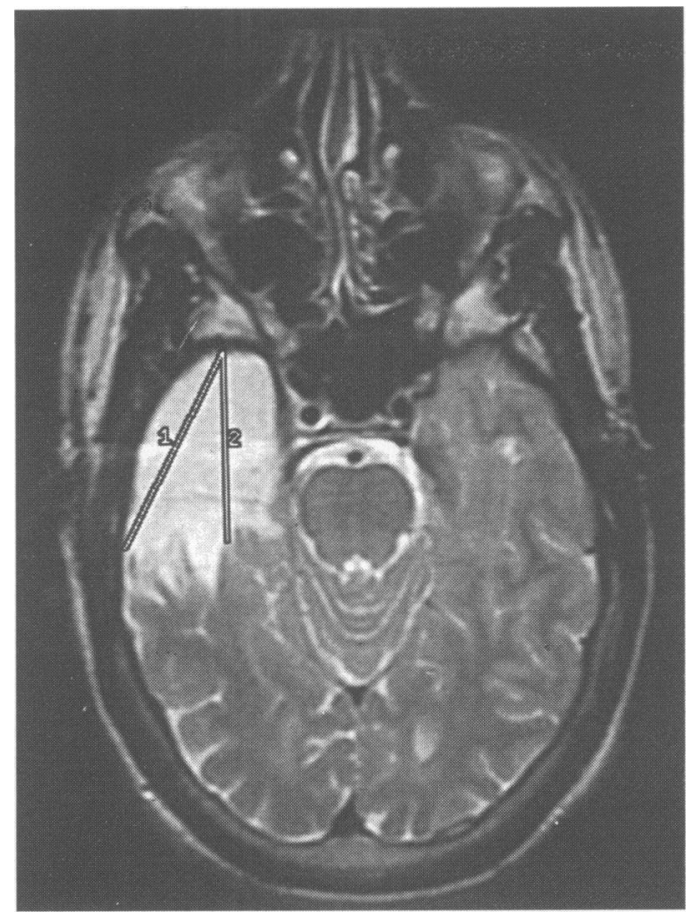

In both the preoperative and postoperative studies the posterior limit of the hippocampus was defined as appearing on the coronal slice where the fornix length was maximal. ${ }^{23} 30 \mathrm{On}$ the preoperative study the volume and length of the affected hippocampal formation (including alveus and fimbria) were measured. Also, for each patient a hippocampal area morphometric map was constructed according to our previously described method, ${ }^{23}$ to show the extent and position of any hippocampal volume loss. As the preoperative and postoperative studies had a common defined point for the posterior hippocampal limit it was possible to overlay the hippocampal resection margins on the preoperative graphs (see fig 4). The area beneath the graph and bound by the resection margins thus defined the hippocampal resection volume. Knowing the total resection volume and the volume of the hippocampal resection the non-hippocampal ("lateral") resection volume could be calculated by subtraction.

Thus for each patient the MRI variables obtained were: (1) hippocampal volume ( $\mathrm{mm}^{3}$ preoperative study); (2) hippocampal resection volume $\left(\mathrm{mm}^{3}\right.$; preoperative hippocampal volume bound by the resection margins obtained from the postoperative study); (3) percentage of hippocampal volume resected $((2) /(1))$; (4) hippocampal length ( $\mathrm{mm}$; preoperative study); (5) length of hippocampal resection ( $\mathrm{mm}$; postoperative study); (6) percentage hippocampal length resected $((5) /(4)) ;(7)$ total resection volume $\left(\mathrm{mm}^{3}\right.$; postoperative study); (8) volume of lateral structures resected $\left(\mathrm{mm}^{3}\right)((7)-(2))$; (9) linear extent of resection of lateral structures (measured on the T2 axial MRI where the resection appeared maximal (fig 3 ). There are various choices of linear measurement with which to estimate the extent of lateral resection (such linear measurements are extremely difficult to standardise on a computer screen let alone by the surgeon at operation). Two such measurements, which could be expected to correlate with the extent of lateral resection, were assessed-namely, (1) distance from lateral cortical resection margin to temporal pole; (2) orthogonal distance from lateral cortical resection margin in the axis of the temporal lobe to the level of the temporal pole; (10) hippocampal morphometric resection graphs (preoperative study with resection overlay (fig 4).

\section{Results (table and figs 4-8)}

The table shows variables obtained by MRI for the 10 cases.

Volumes are given to the nearest $5 \mathrm{~mm}^{3}$ and lengths to the nearest $0.5 \mathrm{~mm}$.

The range of resection volumes in this small sample of 10 cases shows the large variability that can occur between cases having a "standardised" procedure (all except case 9 had a non-tailored anterior temporal lobectomy). This variability is seen with the total $\left(6155-23690 \mathrm{~mm}^{3}\right)$, hippocampal (680-1665 $\left.\mathrm{mm}^{3}\right)$, and non-hippocampal (4790-22 $025 \mathrm{~mm}^{3}$ ) resection volumes. The variability in the three measures was similar between surgeon $A$ and surgeon $B$.

In these 10 cases the total resection volume was significantly correlated with the proportion of hippocampal volume resected (correlation coefficient $0.72, \mathrm{p}<0.05$ ) - that is, a larger total resection was significantly associated with a more complete hippocampal resection. With respect to the hippocampal resection itself we believe that the proportion of hippocampal formation resected is of more importance than the actual amount as the more atrophic is the structure the shorter and smaller it will be. Furthermore, there is great variability in the volume and length of normal hippocampi, making comparison in absolute terms problematic. For example, case 10 had $58 \%$ of the hippocampal volume resected against $85 \%$ in case 5 , despite the fact that the actual resection volume was greater (1430 $\mathrm{mm}^{3} v 1330 \mathrm{~mm}^{3}$ ). This indicates that case 5 had a more complete resection of a more atrophic (and therefore diseased) hippocampus. Figures 5 and 6 show the relation between the length and volume of hippocampal resection expressed in absolute and in percentage terms. In both instances the simple linear measurements correlate well with the volumetric data (correlation coefficients of 0.77 (absolute measurements) and 0.93 (proportions)). Although this correlation is greater with the resection proportions than with the absolute resection amounts in both cases this reached statistical significance $(p<0.001$ and $p<0.01$ respectively). In other words the simple linear measurements of hippocampal resection with our technique are a good indication of the hippocampal resection volume. By contrast, both linear measurements (lengths 1 and 2, fig 3 ) of the extent of the lateral resection correlated extremely poorly with the lateral resection volume (correlation 

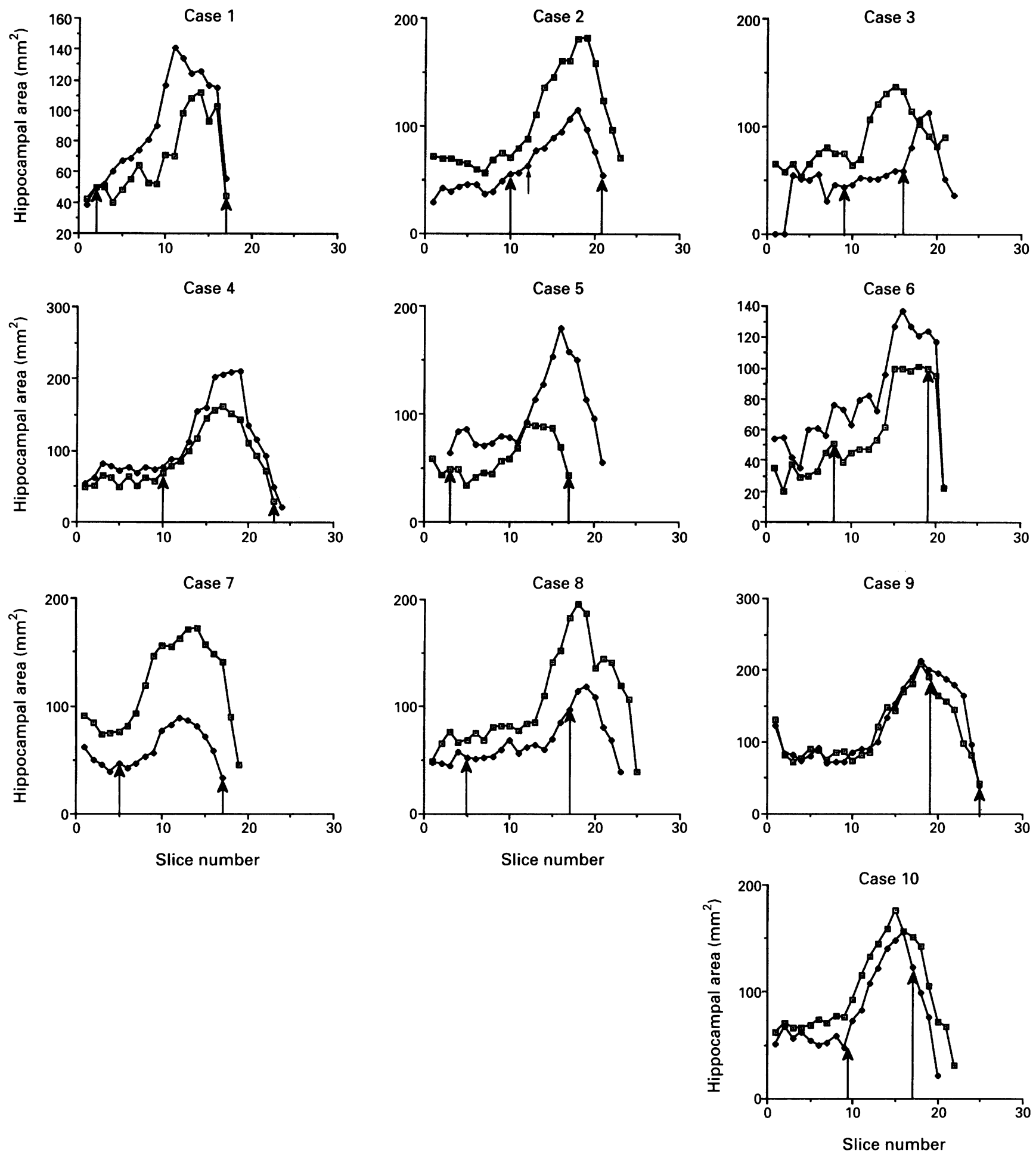

Figure 4 Morphometric graphs of hippocampal resection area for each patient. The variability in hippocampal volume loss and the varying degree of correlation between the surgical resection and volume loss is clearly shown in all 10 cases. The slices are numbered passing anteriorly from the posterior hippocampal limit at slice 1, and are $1.5 \mathrm{~mm}$ thick. The hippocampal area in $\mathrm{mm}^{2}$ is obtained directly from the console screen by pixel counting. Black squares = right hippocampus; white squares = left hippocampus. Arrows indicate resection margins of the diseased hippocampus. In case 2 the slice 18 mm anterior to the posterior hippocampal limit corresponds to figs 1 and 2 and is annotated with a small arrow.

coefficients of $0.49(1)$ and $0.47(2), \mathrm{p}>0.2$ (1 and 2)). Figures 7 and 8 show this graphically.

Measurements of the hippocampal surgical specimen by the pathologist had been possible in eight cases and the resection lengths thus obtained were in broad agreement with those obtained by MRI (table; correlation coefficient $0.81, \mathrm{p}<0.01$ ), and were mostly within 2 $\mathrm{mm}$, although in one case (case 5) there was a difference of $7 \mathrm{~mm}$. Caution should be used in the interpretation of these retrospective findings however, for although the mesial structures were by and large removed en bloc the amount of material lost during the dissection (by fine suction and diathermy) is unknown and the pathologist simply measured the specimen that he had received in the normal way.

The morphometric graphs of hippocampal 
MRI variables for 10 cases of surgically treated temporal lobe epilepsy

\begin{tabular}{|c|c|c|c|c|c|c|c|c|c|c|c|}
\hline \multirow[b]{2}{*}{$\begin{array}{l}\text { Case } \\
\text { No }\end{array}$} & \multicolumn{7}{|c|}{ Hippocampal formation } & \multirow[b]{2}{*}{$\begin{array}{l}\text { Lateral } \\
\text { resection } \\
\text { volume } \\
\left(\mathrm{mm}^{3}\right)\end{array}$} & \multirow[b]{2}{*}{$\begin{array}{l}\text { Lateral } \\
\text { resection } \\
\text { length (1) } \\
(\mathrm{mm})\end{array}$} & \multirow[b]{2}{*}{$\begin{array}{l}\text { Lateral } \\
\text { resection } \\
\text { length (2) } \\
(\mathrm{mm})\end{array}$} & \multirow[b]{2}{*}{$\begin{array}{l}\text { Total } \\
\text { resection } \\
\text { volume } \\
\left(\mathrm{mm}^{3}\right)\end{array}$} \\
\hline & $\begin{array}{l}\text { Volume } \\
\left(\mathrm{mm}^{3}\right)\end{array}$ & $\begin{array}{l}\text { Length } \\
(\mathrm{mm})\end{array}$ & $\begin{array}{l}\text { Resection } \\
\text { volume } \\
\left(\mathrm{mm}^{3}\right)\end{array}$ & (\%) & $\begin{array}{l}\text { Resection } \\
\text { length } \\
(\mathrm{mm})\end{array}$ & $(\%)$ & $\begin{array}{l}\text { Specimen } \\
\text { length } \\
(\mathrm{mm})\end{array}$ & & & & \\
\hline 1 & 1735 & $25 \cdot 5$ & 1665 & (96) & $22 \cdot 5$ & (88) & 20 & 22025 & 44 & 53 & 23690 \\
\hline 2 & 2000 & 31.5 & 1280 & (64) & 16.5 & (52) & 14 & 12465 & 19 & 29 & 13745 \\
\hline 3 & 1790 & $30 \cdot 0$ & 680 & (38) & 10.5 & (35) & 10 & 10030 & 25 & 27 & 10710 \\
\hline 4 & 2030 & 34.5 & 1440 & (71) & $20 \cdot 5$ & (59) & ND & 21540 & 38 & 44 & 22980 \\
\hline 5 & 1530 & $25 \cdot 5$ & 1330 & (85) & $21 \cdot 0$ & (82) & 14 & 18250 & 42 & 52 & 19550 \\
\hline 6 & 1795 & 31.5 & 1365 & (76) & 20.5 & (65) & 20 & 4790 & 41 & 50 & 6155 \\
\hline 7 & 1525 & 25.5 & 1160 & (76) & 18.0 & (71) & 15 & 17240 & 26 & 31 & 18400 \\
\hline 8 & 1520 & 34.5 & 1170 & (77) & 18.0 & (52) & 20 & 18715 & 36 & 39 & 19885 \\
\hline 9 & 4130 & $37 \cdot 5$ & 785 & (19) & $9 \cdot 0$ & (24) & ND & 4955 & 21 & 21 & 5740 \\
\hline 10 & 2475 & $30 \cdot 0$ & 1430 & (58) & $12 \cdot 0$ & (40) & 10 & 10450 & 26 & 38 & 11880 \\
\hline
\end{tabular}

$\mathrm{ND}=$ Not determined; lengths were estimated to the nearest $0.5 \mathrm{~mm}$ and volumes to the nearest $5 \mathrm{~mm}^{3}$.

resection for each patient (fig 4) show the relation between the position of the hippocampal resection and the loss of hippocampal volume. In patient 9 for instance, the small resection (stereotactic amygdalohippocampectomy) seems to be extremely well correlated with the localised area of anterior hippocampal volume loss. By contrast, in case 3 the resection has not included $10.5 \mathrm{~mm}$ of atrophic hippocampus posteriorly (there were seven MR slices behind the posterior limit of the hippocampal resection).

\section{Discussion}

We have described a method for measuring surgical resection of the hippocampal (mesiobasal) and lateral (non-hippocampal) temporal lobe compartments by high resolution MRI. This study came about from the impression gained by our routine use of postoperative MRI in surgery for epilepsy ${ }^{29}$ that temporal lobe resections for epilepsy may be more variable than the term "standard" temporal lobectomy would suggest and furthermore that the other methods used routinely for estimating the resection amount, such as the manual linear measurements performed at the time of surgery or from postoperative CT or $\mathrm{MRI},{ }^{33-37}$ are relatively crude. As a result any audit of the efficacy of differing surgical operations is hampered by lack of information regarding the surgery itself.

There have been several attempts to quantify temporal lobe resections by compartmentalisation techniques. ${ }^{827283132}$ These methods were designed to answer specific questions regarding temporal lobe epilepsy, however, and are not applicable to other types of resection, do not measure the volume of brain resection in absolute terms, and are laborious to perform. By contrast, we have developed a simple methodology based on $1.5 \mathrm{~mm}$ thick contiguous MRI to provide sufficient sampling of the area of interest that is applicable to surgery for all types of epilepsy. In this paper we have described its use in temporal lobe resections for hippocampal sclerosis. A similar methodology is currently being applied to cases of lesional epilepsy. Our method does not use an indirect scoring system to estimate the extent of resection but instead calculates the linear and volumetric resection indices directly. Furthermore by applying the identical MRI protocol to our preoperative studies we have been able to maximise the information of each and accurately correlate the resection with the preoperative imaging abnormality. This is important because of the variability in the temporal lobe to be operated on and the operative resection itself.

Routine use of both preoperative and

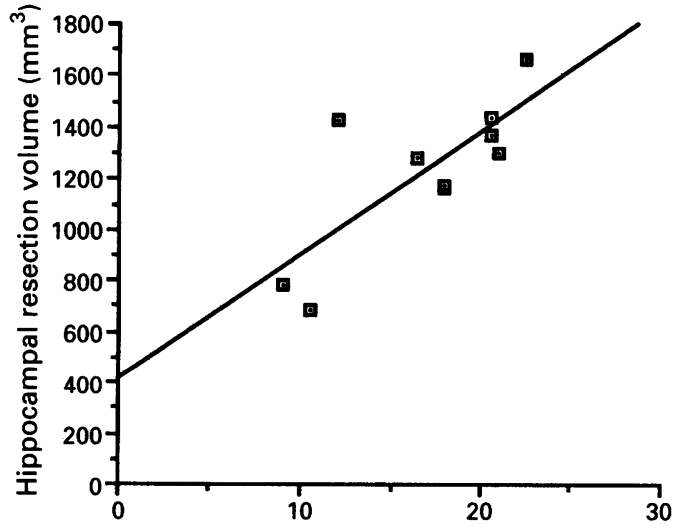

Hippocampal resection length $(\mathrm{mm})$

Figure 5 Relation between hippocampal resection volume and length. Correlation coefficient $0.77(p<0.01)$. There is good correlation between the two variables. 


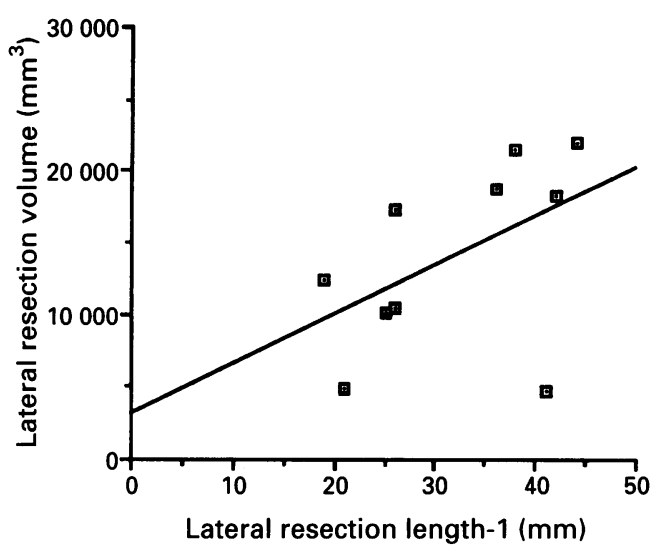

Figure 7 Relation between length 1 (lateral cortical resection margin measured to the temporal pole) and the lateral resection volume. Correlation coefficient $0.49(p>$ $0 \cdot 2)$. There is poor correlation between the variables.

postoperative volumetric MRI will make important contributions in some key areas in surgery for epilepsy. Not only will there be feedback for the surgeon on his success at achieving the intended resection in the individual patient (and this will become more important as the resections become more selectively tailored to the preoperative imaging and abnormalities on EEG), but in addition, analysis of the results of the differing surgical techniques used in medically intractable temporal lobe epilepsy may now be compared. Such image directed audit of surgery for temporal lobe epilepsy therefore works on two levels; completing the feedback loop for the individual surgeon but also more generally in allowing proper and valid comparisons of surgical results.

In conclusion we have found our MRI based technique to be simple and easy to apply. We have been able to document the resection volumes of the temporal lobe compartments and correlate the hippocampal resection with the volume loss seen after operation. Although simple linear measurements of the hippocampal resection correlated well with the resection volume this was not the case with the non-hippocampal or "lateral" resection where linear measurements proved very unreliable in indicating the actual volume of resected brain. As the hippocampal resection volume is smaller than the overall resection volume this unreliability is true of the total as well as the lateral resection volumes and shows the problems of overinterpretation of measurements taken by the surgeon at the time of surgery.

There is considerable variation in the resection volumes of all compartments and in the degree to which the hippocampal resection correlates with the preoperative imaging abnormalities. These may have prognostic significance and we are currently performing follow up studies on a larger cohort of patients to test these hypotheses.

We thank Dr John Duncan and Mr William Harkness for allowing us to include their patients in this study. This research has been generously supported by the Sir Jules Thorn Trust.

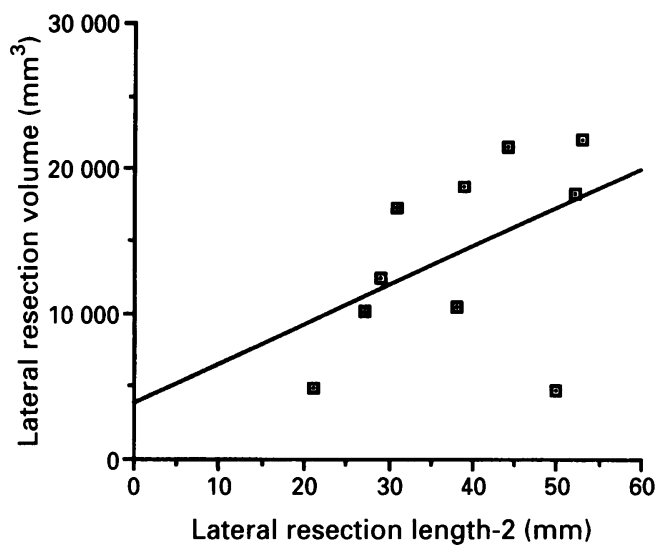

Figure 8 Relation between length 2 (resection margin measured along the axis of the temporal lobe to the temporal pole) and the lateral resection volume. Correlation coefficient $0.47(p>0.2)$. There is poor correlation between the variables.

1 Cahan LD, Sutherling W, McCullough MA, Rausch R, Engel J Jr, Crandall PH. Review of the 20-year UCLA experience with surgery for epilepsy. Cleveland Clinic experience with surgery

2 Davies KG, Weeks RD. Temporal lobectomy in intractable epilepsy: experience with 58 cases over 21 years. Br $\mathcal{F}$ Neurosurg 1993;7:23-34.

3 Elwes RDC, Dunn G, Binnie CD, Polkey CE. Outcome following resective surgery for temporal lobe epilepsy: a prospective follow up study of 102 consecutive cases. f Neurol Neurosurg Psychiatry 1991;54:949-52.

4 Falconer MA, Serfetinides EA. A follow-up study of surgery in temporal lobe epilepsy. $f$ Neurol Neurosurg Psychiatry 1963;26:154-65.

5 Garcia Sola R, Miravet J. Surgical treatment of epilepsy. Results after a minimum follow-up of five years. Acta Neurochir Suppl (Wien) 1991;52:157-60.

6 Glasser GH. Treatment of intractable temporal lobe limbic epilepsy (complex partial seizures) by temporal lobectomy. Ann Neurol 1980;8:455-9.

7 Meyer FB, Marsh WR, Laws ER, Sharbrough FW. Temporal lobectomy in children with epilepsy. f Neurosurg 1986;64:371-6.

8 Jack CR Jr, Sharbrough FW, Marsh WR. Use of MR imaging for the quantitative evaluation of resection for temporal lobe epilepsy. Radiology 1988;169:463-8.

8 Ojemann GA. Surgical therapy for medically intractable epilepsy. $\mathcal{F}$ Neurosurg 1987;66:489-99.

9 Rougier A, Dartigues J-F, Commenges D, Claverie B, Loiseau P, Cohadon F. A longitudinal assessment of seizure outcome and overall benefit from 100 corticectomies for epilepsy. $f$ Neurol Neurosurg Psychiatry 1992;55:762-7.

10 Spencer DD, Spencer SS. Surgery for epilepsy. Neurol Clin 1985;3:313-30.

11 Ojemann GA. Different approaches to resective epilepsy surgery: standard and tailored. Epilepsy Res 1992;5 surgery: standa

12 Falconer MA, Hill D, Meyer A, Mitchell W, Pond DA. Treatment of temporal lobe epilepsy by temporal lobectomy. A survey of findings and results. Lancet 1955; i:827-35.

13 Penfield W and Baldwin $M$. Temporal lobe seizures and the technique of subtotal temporal lobectomy. Ann Surg 1952;136:625-34

14 Walker AE. Temporal lobectomy. $f$ Neurosurg 1967; 26:642-9.

15 Niemeyer $P$. The transventricular amygdalo-hippocampectomy in temporal lobe epilepsy. In: Baldwin $\mathrm{N}$, Bailey P, eds. Temporal lobe epilepsy. Springfield, Ill: Ch C Thomas, 1958:461-82.

16 Kelly PJ, Sharbrough FW, Kall BA, Goerss SJ. Magnetic resonance imaging-based computer-assisted stereotactic resonance imaging-based computer-assisted stereotactic
resection of the hippocampus and amygdala in patients resection of the hippocampus and amygdala in patients
with temporal lobe epilepsy. Mayo Clin Proc 1987; with tempor.

17 Kim HI, Olivier A, Jones-Gotman M, Primrose D, Andermann F. Corticoamygdalectomy in memoryimpared patients. Stereotact Funct Neurosurg 1992; 58:162-7.

18 Kratimenos GP, Pell MF, Thomas DGT, Shorvon SD, Fish DF, Smith SJN. Open selective amygdalohippocampectomy for drug resistant epilepsy. Acta Neurochir (Wien) 1992;116:150-4.

19 Spencer DD, Spencer SS, Mattson RH, Williamson PD, Novelly RA. Access to the posterior medial temporal lobe structures in the surgical treatment of temporal lobe epilepsy. Neurosurgery 1984;15:667-71.

20 Yasargil MG, Teddy PJ, Roth P. Selective amygdalohippocampectomy: Operative anatomy and surgical hippocampectomy: Operative anatomy and surgical 93-123.

21 McMackin D and Staunton, H. Surgery for temporal lobe 
epilepsy- a review. Fournal of the Irish College of Physicians and Surgeons 1991;20:193-7.

22 Cascino GD, Jack CR Jr, Parisi JE, et al. MRI in the presurgical evaluation of patients with frontal lobe epilepsy and children with temporal lobe epilepsy: pathologic correlation and prognostic importance. pathologic correlation and

23 Cook MJ, Fish DR, Shorvon SD, Straughan K, Stevens JM. Hippocampal volumetric and morphometric studies in frontal and

24 Jack CR Jr, Sharborough FW, Cascino GD, Hirschorn KA, O'Brien PC, Marsh WR. Magnetic Resonance Image-based hippocampal volumetry: correlation with outcome after temporal lobectomy. Ann Neurol 1992;31:138-46.

25 Jackson GD, Berkovic SF, Tress BM, Kalnins RM, Fabinyi GCA, Bladin PF. Hippocampal sclerosis may be reliably detected by magnetic resonance imaging. Neurology 1990;40:1869-75.

26 Kuzniecky R, Burgard S, Faught E, Morawetz R, Bartolucci A. Predictive value of magnetic resonance imaging in temporal lobe epilepsy. Arch Neurol 1993;50:65-9.

27 Awad IA, Katz A, Hahn JF, Kong AK, Ahl J, Luders H. Extent of resection in temporal lobectomy for epilepsy: 1. Interobserver analysis and correlation with seizure outcome. Epilepsia 1989:30:756-62.

28 Katz A, Awad IA, Kong AK, Chelune GJ, Naugle RI, Wyllie E, Beauchamp G, Luders $H$. Extent of resection in temporal lobectomy for epilepsy. II. Memory changes and neurologic complications. Epilepsia 1989;30 763-71.
29 Kitchen ND, Thomas DGT, Shorvon SD, Fish DR, Stevens JM. Volumetric analysis of epilepsy surgery resections using high resolution magnetic resonance imaging- technical note. Br f Neurosurg 1993;7:651-6.

30 Kitchen ND, Thomas DGT, Thompson PJ, Shorvon SD, Fish DR. Open stereotactic amygdalohippocampectomy- Clinical, psychometric and MRI follow-up. Acta tomy- Clinical, psychometric and

31 Nayel MH, Award IA, Luders H. Extent of mesiobasal resection determines outcome after temporal lobectomy for intractable complex partial seizures. Neurosurgery 1991;29:55-61.

32 Siegel AM, Wieser HG, Wichmann W, Yasargil GM. Relationships between MR-imaged total amount of tissue removed, resection scores of specific mediobasal limbic subcompartments and clinical outcome following selective amygdalohippocampectomy. Epilepsy Res 1990;6:56-65.

33 Bengzon AR, Rasmussen T, Gloor P, Dussault J, Stephens M. Prognostic features in the surgical treatment of temporal lobe epileptics. Neurology 1968;18:717-31.

34 Jensen I and Vaernet K. Temporal lobe epilepsy: Followup investigation of 74 temporal lobe resected patients. up investigation of 74 temporal lobe rese

35 Marino $\mathrm{R}$ and Rasmussen T. Visual field changes after temporal lobectomy in man. Neurology 1968;18:825-35.

36 Morris AA. Temporal lobectomy with removal of uncus, hippocampus, and amygdala. Arch Neurol Psychiatr 1956;76:479-96

37 Wolf RL, Ivnik RJ, Hirschorn KA, Sharbrough FW, Cascino GD, Marsh WR. Neurocognitive efficiency following left temporal lobectomy: standard versus limited resection. $\mathcal{F}$ Neurosurg 1993;79:76-83. 